\title{
Community beliefs and practices about dengue in Puerto Rico
}

\author{
Carmen L. Pérez-Guerra, ${ }^{1}$ Emily Zielinski-Gutierrez, ${ }^{2}$ \\ Danulka Vargas-Torres, ${ }^{1}$ and Gary G. Clark ${ }^{1,3}$
}

Suggested citation Pérez-Guerra CL, Zielinski-Gutierrez E, Vargas-Torres D, Clark GG. Community beliefs and practices about dengue in Puerto Rico. Rev Panam Salud Publica. 2009;25(3):218-26.

ABSTRACT Objective. In spite of long-term endemicity and repeated government and private efforts, effective, sustained community participation for dengue prevention remains a challenge in Puerto Rico. This study explored differences found in interviews conducted in 2001 in attitudes toward dengue and its prevention by respondents' gender and whether they had a prior dengue infection. Findings may be used to develop messages to promote Aedes aegypti control practices. Methods. From September to October 2003, 11 focus groups were conducted in San Juan, Puerto Rico. Fifty-nine persons (35 women, 24 men), $\geq 18$ years of age, who had been identified through the Puerto Rico dengue surveillance system participated in the focus groups. Analysis was based on grounded theory.

Results. Women considered dengue important because of its economic, emotional, and health impact, and they were concerned more often than men about insufficient garbage removal and water disposal. Participants with a previous dengue diagnosis were more concerned about risk of the disease, were more knowledgeable about dengue and its prevention, and recommended use of repellents more often than their counterparts without a previous dengue diagnosis. Barriers to sustained dengue prevention included misconceptions from outdated educational materials, "invisibility" of dengue compared with chronic diseases, and lack of acceptance of responsibility for dengue prevention.

Conclusions. Suggested strategies to motivate residents' actions included working with government agencies to address structural problems that increase mosquito populations, improving access to information on garbage collection and water disposal through telephone hotlines, increasing publicity and information about dengue by mass media campaigns, and educating health professionals.

Key words Dengue, health education, vector control, Puerto Rico.

1 Dengue Branch, Division of Vector-Borne Infectious Diseases, National Center for Zoonotic, VectorBorne, \& Enteric Diseases, Centers for Disease Control and Prevention, San Juan, Puerto Rico. Send correspondence and reprint requests to: Carmen L. Pérez-Guerra, Dengue Branch, Division of VectorBorne Infectious Diseases, Centers for Disease Control and Prevention, 1324 Calle Cañada, San Juan, Puerto Rico 00920-3860; telephone: (787) 706-2399; fax: (787) 706-2496; e-mail: cnp8@cdc.gov

2 Division of Vector-Borne Infectious Diseases, National Center for Zoonotic, Vector-Borne, \& Enteric Diseases, Centers for Disease Control and Prevention, San Juan, Puerto Rico.
Dengue and dengue hemorrhagic fever (DHF) are acute febrile viral infections caused by any of four dengue viruses $(1,2)$. It is a mosquito-borne disease, and the principal vector is Aedes aegypti. In the past 20 years, dengue trans-

\footnotetext{
3 Current address: Mosquito and Fly Research Unit, Center for Medical, Agriculture and Veterinary Entomology, Agriculture Research Service, United States Department of Agriculture, Gainesville, Florida, United States of America.
}

mission and the frequency of epidemics have increased in the tropics and subtropics of the Americas. Dengue is endemic in Puerto Rico and epidemic transmission occurs periodically. In nonepidemic years, reported cases of dengue range from about 3400 to 7000 per year (3). The highest period of disease activity during the 1990s was the 1994 epidemic when 24700 suspected dengue cases were reported (4). 
A. aegypti mosquito control in the Americas and the Caribbean was initiated through large, vertical, almost militaristic programs that combined decreasing the number of mosquito breeding sites and use of insecticides. These government programs were not sustainable over the long term. Since the 1990s, the theoretical focus for dengue prevention shifted to community-based elimination of mosquito breeding sites (5). These approaches, however, have proven difficult to put into practice. Today, dengue is a widespread problem, with at least 35 countries in the Americas and the Caribbean reporting dengue cases and 19 reporting DHF cases (6). The best approaches for truly involving the general population in dengue prevention are a pressing concern.

In Puerto Rico, government efforts, supported by the private sector (i.e., Rotary International), have successfully educated the public about the vector, the transmission cycle, clinical symptoms, and prevention methods $(5,7)$. These efforts promoted household responsibility in eliminating or controlling breeding sites for $A$. aegypti and used insecticides to reduce the adult mosquito population. However, achieving sustained community participation for dengue prevention during periods of low disease activity remains a challenge. We initiated a study to learn how messages and interventions might be improved to achieve sustained dengue prevention practices among community residents.

In 2001, group interviews were conducted in four geographic areas of Puerto Rico (7) to gather information from residents that would help develop more effective messages and strategies to promote community involvement in dengue prevention initiatives and to augment residents' adoption of dengue prevention behaviors. In that study, we found that men and women had similar knowledge, attitudes, and strategies about dengue prevention regardless of their previous dengue diagnosis. However, we found differences by gender related to the type of and most common production sites (7).

This study was conducted to further explore differences noted in 2001 interviews in attitudes toward dengue and its prevention by gender and to investigate whether we find differences by previous dengue infection.

\section{MATERIALS AND METHODS}

From September to October $2003,{ }^{4}$ we conducted 11 focus groups in three municipalities (Carolina, Guaynabo, and San Juan) in the greater San Juan metropolitan area. Focus group participants from these municipalities were divided according to gender and the presence or absence of a previous laboratory-diagnosed dengue infection. For each municipality, we selected a random sample of patients from the Dengue Branch of the Centers for Disease Control and Prevention (CDC) and the Puerto Rico Department of Health (PRDH) dengue surveillance system database who had a positive IgM antibody test for dengue from 1994 to 1999 and were $>18$ years of age. The potential participants identified from the database were contacted by telephone and invited to "participate in a focus group about dengue prevention" until five or more persons from each municipality agreed to participate.

To recruit participants who were not aware of having a previous laboratorydiagnosed dengue infection, investigators contacted the neighbor three houses to the right of a participant with a previous dengue infection. This neighbor was invited to participate in the study if he or she was $>18$ years of age and had no knowledge of a previous dengue infection. Five or more persons in this category from each municipality were enrolled in the study. Each focus group participant received a modest stipend for travel costs.

We formulated five research questions: (1) Are there differences in beliefs, attitudes, and behaviors toward dengue prevention by gender or previous dengue diagnosis? (2) What barriers hinder the adoption of dengue prevention practices? (3) What factors will motivate the adoption of preventive behaviors? (4) Do focus group participants share the same opinions about the best strategies for vector control programs as the participants in the prior study? (5) What do current focus group participants see as compelling dengue prevention messages for specific audiences?

The participants were also asked their opinions about strategies proposed by participants in the 2001 study for

\footnotetext{
4 The protocol for this project was reviewed and approved by the Centers for Disease Control and Prevention Institutional Review Board protocol 3965.
}

the government to initiate to prevent dengue (7). Dengue prevention methods suggested by participants in the 2001 study included (1) house visits, (2) community group discussions and orientations, (3) development of community groups, (4) implementation of laws and fines for violators who keep $A$. aegypti breeding sites at their residences, and (5) a dengue educational media campaign.

A 14-item, open-ended question guide was developed based on the research questions described above and the guide from the 2001 study (7). The 2001 question guide was pretested with 10 members of a church from Carolina. Modifications were made to the 2001 guide to address the new objectives of this study. Before each focus group, informed consent was obtained from each participant. Groups of participants (average five persons) were convened and their responses to the 14-item question guide were annotated and audio taped by the assistant moderator, the third author (D.V.T.). The focus groups were moderated by the first author (C.L.P.G.) to ensure that all participants expressed their opinions.

The term "grounded theory" refers to a qualitative research method in which a theory is developed from data. Responses (data) are grouped in categories, from which large themes or concepts are identified. A content analysis with grounded theory procedures was used to analyze the data generated from the focus groups and to answer the research questions (8-10). Open coding analytical procedures, which identified central categories and subcategories for analysis, were used. In addition, we used axial coding in which the relation between subcategories was determined. We compared results from the focus groups with the 2001 group interviews (7) and results from other published research (11-20).

To enroll 20 dengue-positive focus group participants, 135 telephone calls were made. There was no response or the phone was out of service for 42/135 (31\%) of the calls; $93 / 135(69 \%)$ potential participants were reached, and 45/93 (48\%) agreed to participate in a focus group. Ultimately, only 20/45 (44\%) attended one of the focus group sessions and no information was available about those who did not participate. After the dengue-positive patients had been reached by telephone, 44 neighbors, who had no recollection of a previous dengue infection, were visited; 39/44 (89\%) agreed to par- 
TABLE 1. Categories as identified in transcriptions of 2001 group interviews and 2003 focus groups conducted in Puerto Rico

\begin{tabular}{|c|c|c|}
\hline Category & 2001 & 2003 \\
\hline 1 & $\begin{array}{l}\text { Most important biological, psychological, and social problems } \\
\text { faced by participants in their communities }\end{array}$ & $\begin{array}{l}\text { Most important environmental problems faced by participants in } \\
\text { their communities }\end{array}$ \\
\hline 2 & Knowledge about dengue and $\mathrm{DHF}^{\mathrm{a}}$ and their prevention & Knowledge about dengue and DHF and their prevention \\
\hline 3 & Attitudes about dengue and DHF and their prevention & $\begin{array}{l}\text { Mosquito breeding sites described most frequently by participants, } \\
\text { their function, and person responsible }\end{array}$ \\
\hline 4 & Community behaviors related to dengue and DHF & Attitudes toward dengue and DHF and their prevention \\
\hline 5 & Ideas to encourage the adoption of dengue prevention behaviors & $\begin{array}{l}\text { Current personal behaviors practiced by participants to prevent } \\
\text { dengue }\end{array}$ \\
\hline 6 & Design of a dengue prevention mass media campaign & $\begin{array}{l}\text { Specific actions suggested by participants to avoid potential } \\
\text { breeding sites }\end{array}$ \\
\hline 7 & & $\begin{array}{l}\text { Government strategies discussed by participants to motivate the } \\
\text { adoption of dengue prevention behaviors among the population }\end{array}$ \\
\hline
\end{tabular}

a DHF, dengue hemorrhagic fever.

ticipate and all were present at the group sessions. A total of 59 persons $\geq 18$ years of age-35 women and 24 men-participated in the focus group sessions.

\section{RESULTS}

Analysis of the focus group participants' responses resulted in the identification of 7 large categories and 26 subcategories. These results are presented in Table 1 (categories) and Table 2 (subcategories), with comparisons to the results of the 2001 study (7). Current responses differed by gender and history of dengue diagnosis. For example, environmental problems related to dengue were more important for women than for men. Women described these problems as insufficient garbage collection by the government and garbage disposal in illegal dumps by the public, liquor stores (which store containers for recycling), and tire and auto repair shops (a problem that men supported); mosquito proliferation; and lack of fumigation by the government. In addition, women were more knowledgeable than men about dengue.

Differences by gender were also seen when participants discussed the perceived severity of dengue. For women with a previous dengue diagnosis, dengue was serious because "there is no vaccine" to prevent it, it has a "high incidence" on the island, and it "causes social, economic, job, family, and emotional problems" for both the patient and the government. Contrary to these women, dengue was serious for men because "people think it's just a mosquito bite" and are not aware of its severity.
That is, for women dengue is serious because it is a widespread health problem that affects many people, whereas for men it is "serious" because it can cause grave damage to an individual's health.

Participants with a previous dengue diagnosis, regardless of gender, were more knowledgeable about dengue, its symptoms, complications, and treatment than participants without a previous dengue diagnosis. Both men and women took responsibility for decreasing the number of breeding sites, although women were seen as responsible for breeding sites related to household domestic activities and men were responsible for tires, cars, and rubbish (Table 3 ).

All focus group participants indicated that dengue can be prevented by avoiding and eliminating "stagnant water" or containers with water, but there were some differences by gender and history of previous dengue diagnosis. Women with a previous dengue diagnosis thought that dengue could be prevented by "avoiding mosquito egg [laying]," while women with no prior history of dengue reported that they added drops of chlorine to stored water and surroundings. Women, regardless of previous dengue diagnosis, mentioned fumigation and using insecticides inside the house for preventing dengue, whereas men with a previous dengue diagnosis mentioned using repellents for dengue prevention. Women without a previous dengue diagnosis were more likely than women with a previous dengue diagnosis to voice concern about fumigation and its effect on health (e.g., spraying pesticides may cause respiratory complications such as asthma in their children).
Participants had divided opinions when discussing the first four prevention strategies recommended by participants from the 2001 study. House visits were not seen as appropriate because it was believed that residents usually do not have time to receive visits and reject visits for selling, religious, or educational purposes. Moreover, they expressed the opinion that the population of Puerto Rico is too large for the PRDH to conduct these house visits.

However, some participants thought that house visits with distribution of educational materials and a demonstration of how to locate and discard containers with mosquito larvae was the best strategy, especially if health department staff and community volunteers conducted the visits. They explained that PRDH staff have knowledge about the problem and the volunteers will give a friendly approach to the visit.

Some participants saw community group discussions, orientations, and health fairs with educational materials as the best strategy, while others thought that few people would attend these activities.

The implementation of laws and fines was not seen as a good strategy by almost all men, contrary to men from the 2001 study who suggested implementing fines for people who keep mosquito production sites on their property. However, most women in this study supported fining violators and said that these fines should be applied after house visits and that violators should be monitored at least once.

The following government actions by type of container were suggested: (1) de- 
TABLE 2. Subcategories as identified in transcriptions of 2001 group interviews and 2003 focus groups conducted in Puerto Rico

\begin{tabular}{|c|c|c|}
\hline Subcategory & 2001 & 2003 \\
\hline 1 & Most important problems in the community & Waste \\
\hline 2 & Most important health problems in the community & Lack of maintenance of abandoned houses, buildings, and green areas \\
\hline 3 & Definition of dengue & Mosquitoes \\
\hline 4 & Definition of $\mathrm{DHF}^{\mathrm{a}}$ & Lack of fumigation \\
\hline 5 & Dengue and DHF symptoms & Dengue definition, symptoms, treatment \\
\hline 6 & Relationship between Aedes aegypti and dengue & DHF definition, symptoms, treatment \\
\hline 7 & Relationship between Aedes aegypti and garbage and containers with water & Aedes aegypti relation to dengue \\
\hline 8 & Aedes aegypti breeding sites in their communities & Aedes aegypti relation to garbage \\
\hline 9 & Definition of "important problem" & Aedes aegypti relation to containers with water \\
\hline 10 & Definition of "prevention" & Breeding containers \\
\hline 11 & Definition of "garbage" & Container function \\
\hline 12 & Ideas about dengue & Person responsible for container \\
\hline 13 & Responsibility for eliminating and controlling breeding sites & Participant's perception of dengue \\
\hline 14 & Current personal and household behaviors for preventing dengue & $\begin{array}{l}\text { Responsibility for eliminating and controlling Aedes aegypti breeding } \\
\text { sites }\end{array}$ \\
\hline 15 & Specific actions to eliminate Aedes aegypti breeding sites & Eliminating stagnant water \\
\hline 16 & $\begin{array}{l}\text { Strategies to be implemented by government to promote dengue } \\
\text { prevention }\end{array}$ & Cleaning breeding sites and surroundings \\
\hline 17 & Evaluation of previous dengue prevention campaigns & Changing water \\
\hline 18 & Messages to motivate target audiences & Pouring chlorine into water \\
\hline 19 & Best spokesperson & Fumigation \\
\hline 20 & Best media & Using repellents \\
\hline 21 & Best time & Visiting physicians when suspecting dengue \\
\hline 22 & & House visits \\
\hline 23 & & Community group discussions \\
\hline 24 & & Development of dengue prevention community groups \\
\hline 25 & & Implementation of laws and fines \\
\hline 26 & & Education campaign for community and physicians \\
\hline
\end{tabular}

${ }^{a}$ DHF, dengue hemorrhagic fever.

TABLE 3. Most common breeding sites described by participants, their function, and person responsible, Puerto Rico, 2003

\begin{tabular}{|c|c|c|}
\hline Container & Function & Person Responsible \\
\hline Tires & $\begin{array}{l}\text { Replacement } \\
\text { Retained until carted }\end{array}$ & $\begin{array}{l}\text { Men } \\
\text { Tire shops }\end{array}$ \\
\hline Flower pots/dishes, flower vases, water plants & Decoration & Women \\
\hline $\begin{array}{l}\text { > 1-gallon containers } \\
\text { Milk/soda plastic containers } \\
\text { Buckets/pails }\end{array}$ & $\begin{array}{l}\text { Garbage thrown in yard } \\
\text { Water plants } \\
\text { Wash cars } \\
\text { Mop } \\
\text { Laundry } \\
\text { Water plants } \\
\text { Store water } \\
\text { Reserve parking spaces }\end{array}$ & $\begin{array}{l}\text { Women } \\
\text { Women } \\
\text { Men } \\
\text { Women } \\
\text { Women } \\
\text { Women } \\
\text { Women } \\
\text { Women and men }\end{array}$ \\
\hline Trash cans (industrial/house) & Retain garbage until collected by sanitation services & Industry/condominium management, women \\
\hline Old cars & $\begin{array}{l}\text { Replace damaged auto parts } \\
\text { Retained because of lack of information about collection services }\end{array}$ & $\begin{array}{l}\text { Auto repair shop owners } \\
\text { Men }\end{array}$ \\
\hline $\begin{array}{l}\text { Rubbish (washing machines/refrigerators/ } \\
\text { dead animals) }\end{array}$ & $\begin{array}{l}\text { Retained until collected by sanitation services or thrown in } \\
\text { illegal dumps }\end{array}$ & Householders/senior residents \\
\hline Clogged drainage & No function & Residents/government \\
\hline Rivers/lagoons with garbage & Used as illegal dumps & Residents/government \\
\hline Puddles/high vegetation & No function & No person/agency responsible \\
\hline
\end{tabular}

velop a law to enforce fees for tire recycling like the one developed for car oil, develop an educational program for tire recycling, and create a telephone hotline for discarded tire pickup; and (2) develop a hotline or information group to educate the community about regulations for tire recycling and coordinate collection services.

Similar to the 2001 study, focus group participants recommended an educational, mass media campaign as a government strategy to supplement the above activities. Participants believed that the campaign should include (1) distribution of educational materials in public places such as supermarkets, beaches, restaurants, churches, and health centers; (2) coordination among government agencies and the inclusion of school children to take information about dengue to 
their homes; (3) development of a dramatic and fear-provoking public service announcement (PSA) including dengue definition, prevention methods, and shocking testimonials that would be aired frequently throughout the year; (4) development of a video showing the mosquito, its breeding cycle, most common breeding containers, prevention methods, and symptoms and treatment of dengue and DHF; and (5) education of physicians about dengue diagnosis and treatment. Messages should be delivered mostly by television and newspapers distributed island-wide and regionally. For program spokespersons, participants generally preferred people who had suffered from dengue and represented the audience responsible for the container that produced mosquitoes on the property. Women preferred that PRDH officials send general prevention messages but also suggested that entertainers do it, while men preferred community leaders.

The same three key themes obtained in the 2001 study (7) were also found in the content analysis of transcripts from the current study and thus confirmed earlier results. The first theme, misconceptions about dengue and its vector, included participants' description of the A. aegypti mosquito, the potential breeding habitats and the type of water where the mosquito breeds, and "cleaning" as a central concept for dengue prevention. It also involved the confusion of dengue with the common cold and other similar viral illnesses. The second theme, the "invisibility" of dengue, emphasized the limited discussion of dengue as a health problem in the mass media compared with chronic illnesses. The third theme, responsibility for dengue prevention, presented the importance of individual and government responsibility to control dengue. The issues described under these three themes summarize the main barriers for dengue prevention.

\section{Misconceptions about dengue prevention}

Almost all focus group participants demonstrated correct knowledge about transmission, symptoms, and treatment of dengue and DHF; container conditions conducive to mosquito breeding; and potential breeding containers. Still, most participants had incorrect knowledge about the physical description of $A$. aegypti, confusion about the type of water and place where the vector mosquito breeds, and information that many people confuse dengue with a cold.

These misconceptions influenced participants' attitudes and practices to prevent dengue. First, an incorrect description of the vector mosquito means, as participants said, that they failed to recognize mosquitoes inside their residences as those that transmit dengue and may confuse it with other mosquitoes, thus not perceiving their risk of becoming infected with a dengue virus. Participants also thought they were incapable of avoiding mosquitoes and thus dengue, because mosquitoes are everywhere and are difficult to control, contrary to the fact that if community members eliminate or control potential breeding sites it is possible to reduce A. aegypti abundance indoors. Although most people recognized the need to eliminate accumulated or uncovered water to prevent dengue, some perceived it as a useless effort since mosquitoes are always present. Participants saw mosquitoes as part of the daily life of Puerto Ricans, for which they use repellents, insecticides, and screens with moderate success. For them, the effective strategy against mosquitoes is periodic fumigation by government.

Second, misconceptions about the "type" of water also influenced the attitudes and practices of participants, as most associated clear or clean water only or dirty water only with A. aegypti. Participants thought that if they did not have this specific kind of water, they would not have the vector mosquito and, therefore, did not recognize the need to eliminate any water present in a container to reduce the presence of $A$. aegypti.

Third, while half the participants named bodies of water with garbage as places where $A$. aegypti can breed, the other half said that it can also breed in high vegetation and humid places with puddles, regardless of the presence or absence of garbage. Consequently, they believe it is difficult to eliminate the mosquito and dengue given the ubiquitous humid places and vegetation (Table 3 ).

Fourth, "cleanliness" was seen as central to dengue prevention as participants emphasized cleaning the premises, surroundings, containers, and conducting "collective cleanups" to prevent mosquito breeding. Although it is accurate that cleaning potential containers will prevent the mosquito from breed- ing, participants' understanding that a "clean" or orderly house is free from A. aegypti is not necessarily correct since containers with larvae may still be present but not visible or disorderly (7). For this reason, people might not realize that they are breeding mosquitoes and potentially increasing their risk of exposure to dengue. Such was the case of a female participant who did not identify with the filthy yard in a PSA because her yard appeared "clean" but, after having DHF she found that plates to collect excess water underneath the flower pots in her yard had mosquito larvae.

Fifth, participants also said that the general population and some health professionals confused dengue with a common cold and other respiratory diseases. Puerto Ricans typically do not consider colds to be serious and rarely seek medical treatment for cold symptoms. Since dengue and cold signs and symptoms are similar at the onset, people do not feel threatened and do not seek diagnosis and treatment in a timely manner. When doing so, they feel frustrated, even in DHF cases, by the treatment they receive from hospitals and physicians, the lack of diagnosis, and the delay in receiving laboratory test results. Participants of both genders insisted that physicians and health professionals in emergency rooms are "uninformed" and "needed orientation" to diagnose and treat dengue.

\section{"Invisibility" of dengue}

Similar to 2001 study participants (7), focus group participants indicated that dengue was given little publicity and importance by the population and the government compared with other-particularly chronic-diseases. Female participants defined the concept of an "important problem" as a situation that is presented in the newspapers and on television news programs. Participants said that, because of its limited presence in the media, dengue is not seen as a health priority; therefore, people minimize its importance and they do not feel at risk of contracting it. Although participants considered dengue a serious problem, no dengue PSAs emphasizing control measures for potential breeding sites are routinely broadcast; hence, people are not aware of their consequences. In contrast, private companies have promoted the use of insecticides and repellents only during dengue season. Moreover, 
TABLE 4. Specific actions suggested by participants to avoid potential breeding sites, Puerto Rico, 2003

\begin{tabular}{|c|c|}
\hline Potential breeding site & Suggested action \\
\hline Tires & $\begin{array}{l}\text { Recycle } \\
\text { Plant flowers in them } \\
\text { Store them in dry places } \\
\text { Store them in plastic bags } \\
\text { Call municipality for pickup }\end{array}$ \\
\hline Flower pots with dishes & $\begin{array}{l}\text { Eliminate dishes } \\
\text { Eliminate flower pots } \\
\text { Eliminate water from dishes } \\
\text { Pour small amounts of water into plants } \\
\text { Pour chlorine and chemicals into water in dishes } \\
\text { Put newspaper in dishes to absorb excess water } \\
\text { Pour soil in dishes } \\
\text { Punch holes }\end{array}$ \\
\hline Flower vases & $\begin{array}{l}\text { Change water every day } \\
\text { Add chemical to water }\end{array}$ \\
\hline Water plants & Plant them in soil \\
\hline Buckets and pails & $\begin{array}{l}\text { Check and clean them } \\
\text { Store them upside down } \\
\text { Eliminate water } \\
\text { Store them in dry places } \\
\text { Clean and cover them }\end{array}$ \\
\hline Trash cans & $\begin{array}{l}\text { Cover them } \\
\text { Throw garbage away every day } \\
\text { Punch holes } \\
\text { Clean them with chlorine }\end{array}$ \\
\hline Milk gallons & $\begin{array}{l}\text { Store them in dry places } \\
\text { Store them upside down }\end{array}$ \\
\hline Swimming pools in construction & Cover them with plastic \\
\hline Rubbish & Store in dry places until truck comes \\
\hline All containers & $\begin{array}{l}\text { Recycle } \\
\text { Check for and eliminate stagnant water }\end{array}$ \\
\hline
\end{tabular}

participants said that dengue cases are not recognized by the government for political reasons (7), "which reacts with fumigation only when many people get sick." For these reasons, participants said that the population does not eliminate $A$. aegypti breeding sites.

\section{Responsibility for dengue prevention}

Concurring with results from the 2001 study (7), responsibility for dengue prevention also emerged as the third theme and was a central concept identified by focus group participants to motivate the population to take preventive actions. Participants agreed that the population was responsible for practicing behaviors to prevent dengue (Table 4), but they also demanded "active participation by the government."

Besides fumigation, participants expected the government to solve problems with the infrastructure and public services related to dengue prevention. For example, they insisted on improving potable water services, enhancing waste and rubbish collection services, and establishing better strategies for tire collection and recycling. Fees for taking refuse to the landfill by the private sector were not acceptable to many participants, as they view waste disposal as the government's responsibility. These fees for waste disposal were barriers to the proper disposal of waste and prevention of breeding sites.

The government's lack of involvement in maintaining public buildings, green areas, and water service were barriers to community-wide dengue prevention. When public buildings and green areas are not maintained, people use them as illegal dumps. People also store water in their houses because water services are inadequate.

Additionally, participants expected the government to continue educating the public about the mosquito vector and its breeding sites, dengue and its symptoms, and diagnosis and treatment of dengue. They expect the government to suggest behaviors to prevent $A$. aegypti breeding throughout the year, rather than only during "dengue" season. Participants also advised using island-wide and regional newspapers and the radio to inform the public about localized outbreaks instead of ignoring or hiding the problem for political purposes.

\section{DISCUSSION}

The purpose of this study was to identify differences in knowledge, beliefs, attitudes, and practices about dengue prevention in focus groups with men and women with and without a prior dengue infection and to compare the differences with those found in the 2001 study (7). While there were few differences between the two studies, those that existed were interesting. New barriers mentioned in this study involved the payments and fees required for recycling and waste collection and the perception of health professionals' lack of knowledge about how to diagnose and treat dengue.

However, participants from both studies reiterated that a collective response was needed to prevent dengue, since it is a problem generated by both the government and the community. Whereas the 2001 study participants developed a list of the four best strategies for dengue prevention (7), the focus group participants agreed that none of those four would be the best strategy to promote the adoption of preventive behaviors but that a strategy integrating all four could help increase awareness of dengue prevention. Instead, they suggested developing telephone hotlines to improve tire, waste, and rubbish pickup and eliminating payment and fees to dispose of rubbish in landfills.

Another difference was that women participants in the 2001 study supported fumigation by the government as the principal strategy to prevent dengue, while some women without a previous dengue diagnosis from the focus groups questioned its effectiveness and feared that it could be harmful to their health. No major differences were found between 2001 study participants and those from this study when their knowledge, beliefs, attitudes, and practices were compared.

We found that differences by gender did exist. Compared with men, women thought dengue was a serious disease because of the burden and impact to society. Men thought it was serious because of an individual's lack of perceived health risk. Women also were 
more concerned about infrastructure problems potentially contributing to increased dengue transmission. In addition, women were seen as responsible for most breeding sites related to domestic activities, while men were responsible for tire and rubbish removal.

Most of these findings are consistent with the cultural values and the social norms of Puerto Rico. Although many men actively participate in domestic and health issues, society continues to perceive women as responsible for the household and the health of family members. In addition, many women in Puerto Rico are single mothers and household heads. These findings suggest that compelling messages about dengue prevention need to target men's and women's issues differently and directly.

Disparities by history of a previous dengue diagnosis revealed that participants with a previous dengue diagnosis were more concerned about other people's risk of contracting dengue and were more knowledgeable about dengue and about effective prevention practices than participants without this life experience. Participants with a previous dengue diagnosis also supported the use of repellents to avoid mosquito bites-and hence dengue-more than their counterparts. For these reasons, it is important to consider testimonials using people with a previous dengue diagnosis as spokespersons for educational campaigns.

The CDC had promoted the use of repellents for tourists visiting dengue endemic areas including Puerto Rico and for other mosquito-borne diseases such as West Nile virus. In the past, private companies in collaboration with government agencies financed the preparation and production of educational materials including preventive practices for specific breeding sites. This collaboration was partially discontinued because it was thought that the materials sent contradictory messages to the population (e.g., avoiding bites by using chemicals versus getting rid of mosquito breeding sites) and the issue of including brand names was complicated for government agencies. Rather than avoiding this issue, the appropriate use of repellents and insecticides can be promoted as a strategy complementary to the primary strategy of eliminating breeding sites.

Similar barriers to dengue prevention were found among participants from this study and from the 2001 study (7). In summary, the lack of importance given to dengue limits the public's interest in carrying out dengue prevention actions. For participants, the lack of importance given to dengue was reflected by the lack of government involvement in solving underlying infrastructure problems associated with dengue transmission, the lack of publicity about dengue, and the lack of fumigation.

Gubler and Clark (5) identified the lack of planned urbanization and inadequate potable water and waste disposal services as infrastructural problems contributing to dengue transmission. The lack of involvement by the community was reflected by the community's perceived low risk of contracting dengue, the inability of the population to differentiate $A$. aegypt $i$ and effectively avoid it, and the lack of knowledge to recognize the type of water where A. aegypti breeds and to differentiate dengue symptoms in contrast to those caused by colds and other viral diseases that are not considered to be life-threatening to the population.

Lloyd et al. (18) found that for residents in Mérida, Mexico, it was important to explain the presence of other mosquito species after conducting dengue prevention activities in order to get the community to sustain them.

Panagos et al. (19) also found that twothirds of residents surveyed in Grenada could name mosquitoes as dengue vectors but could not identify $A$. aegypti, making it difficult to implement control measures.

Entomologic studies have also demonstrated that $A$. aegypti develops in containers with standing water and organic material that gets darker over time (12), a fact that participants did not know. The confusion about the type of water and the distorted description of the mosquito may come from earlier educational materials that showed an enlarged image of the mosquito or a cartoon and demonstrated containers with clean water. These materials make it difficult for the public to recognize $A$. aegypti in their households and to look for potential breeding sites (7). The CDC recently developed educational materials that included real visuals of the mosquito that, although enlarged, specified its real measurements in addition to the various types of water where it breeds.

Previous studies in Brazil (11), Colombia (14), the Dominican Republic $(15,16)$, Mexico $(18,20)$, and Puerto Rico $(7,17)$ also found that participants confused dengue with other febrile and respiratory illnesses that are not considered serious health problems by participants and are not related to mosquitoes. Hence, participants did not take prevention actions to avoid a dengue illness. Also, Claro et al. (13) analyzed 11 published articles related to knowledge, attitudes, and practices about dengue in various countries and found that the association of dengue with milder febrile, respiratory, and viral illness resulted in a lack of concern by the population. The association of dengue with other febrile diseases also reduced the association between the mosquito vector and dengue.

The consistency between this study and the 2001 study gives us confidence that these views cover many of the important barriers to dengue prevention in Puerto Rico. Furthermore, similar results were found in research conducted in other dengue endemic countries (11-21). However, qualitative research findings cannot be generalized since the selected samples do not represent the entire population. In addition, underrepresentation of participants with a previous dengue diagnosis could have biased our results.

\section{CONCLUSIONS}

On the basis of participants' responses, the strategies that would motivate residents to implement dengue prevention actions include the integrated involvement of government agencies improving potable water services in communities with reduced access, enhancing waste collection services by reducing waiting periods for pickup, and providing telephone numbers to improve access to information about these services. Proactive actions could also include establishing better strategies for tire collection and recycling and offering carting and recycling for free. While the community does not want to pay for these services, they accept a municipality tax of $1 \%$ that was implemented in Puerto Rico in 2006. A percentage of this tax could be used for these infrastructure improvements.

Although participants demonstrated concern about the feasibility of conducting island-wide house visits, this activity, supplemented with educational materials, could be implemented during localized outbreaks in specific communities with the collaboration of community 
groups and health officials. A mass media campaign through island-wide and regional newspapers, television newscasts, and radio programs could also complement this effort and address knowledge gaps about dengue and its prevention. This media campaign would also increase publicity and information about dengue, making it a visible priority for the government and the community.

Compelling campaign messages must contrast dengue and DHF symptoms and their differences from other respiratory and viral diseases and should emphasize the symptoms that should trigger persons to seek medical attention to avoid complications. PSA and educational materials should also include specific prevention practices directed to the member of the household that relates to the container or the function it plays in the household. Information about dengue incidence, outbreaks, and out- break locations should be published in the media. Moreover, since dengue is a reportable disease by law in Puerto Rico, the government could require continuing education programs for health professionals to refresh their knowledge about dengue diagnosis, treatment, and prevention.

The CDC Dengue Branch and PRDH have a passive, laboratory-based surveillance system for dengue that identifies outbreaks and their geographic location (22). In addition, the PRDH has a response protocol for use during epidemics that covers community alerts and education, diagnosis, medical treatment, and hospitalizations $(22,23)$. This protocol has been disseminated in newspapers and newscasts when necessary and could be used for the development of educational materials.

To evaluate the government practices suggested by focus group participants, we are conducting a community project that uses home visits and the participation of community leaders to control and prevent dengue. During the household visit, a dengue educational brochure is discussed and a survey of the yard is conducted to teach homeowners how to identify and discard A. aegypti breeding sites. In addition, we are conducting a content analysis of newspaper articles to better understand the social construct of dengue presented by the most widely read newspapers in Puerto Rico. Also planned are health care provider interviews to assess knowledge about dengue in Puerto Rico and its diagnosis and treatment.

Disclaimer. The findings and conclusions in this report are those of the authors and do not necessarily represent the views of the CDC or the Agency for Toxic Substances and Disease Registry.

\section{REFERENCES}

1. World Health Organization. Strengthening implementation of the global strategy for dengue fever/dengue haemorrhagic fever prevention and control: report of the informal consultation. WHO Report HO/CDS/ [DEN]/IC/2000.1. Geneva: WHO; 1999.

2. Gubler DJ. Epidemic dengue/dengue hemorrhagic fever as a public health, social and economic problem in the 21st century. Trends Microbiol. 2002;10:100-3.

3. Rigau-Pérez JG, Ayala-López A, Vorndam AV, Clark GG. Dengue activity in Puerto Rico during an inter-epidemic period: 1995-1997. Am J Trop Med Hyg. 2001;64(1, 2):75-83.

4. Rigau-Pérez JG, Vorndam AV, Clark GG. The dengue and dengue hemorrhagic fever epidemic in Puerto Rico: 1994-1995. Am J Trop Med Hyg. 2001;64(1, 2):67-74.

5. Gubler DJ, Clark GG. Community involvement in the control of Aedes aegypti. Acta Trop. 1996;(61):169-79.

6. Pan American Health Organization. 2006: number of reported cases of dengue and dengue hemorrhagic fever (DHF), region of the Americas (by country and subregion). Washington, D.C.: PAHO; 2006. Available from: http://www.paho.org/english/ad/ $\mathrm{dpc} / \mathrm{cd} /$ dengue-cases-2006.htm. Accessed 28 March 2007.

7. Pérez-Guerra CL, Seda H, García-Rivera EJ, Clark GG. Knowledge and attitudes in Puerto Rico concerning dengue prevention. Rev Panam Salud Publica. 2005;17(4):243-53.

8. Glaser B, Strauss A. The discovery of grounded theory: strategies for qualitative research. Chicago: Aldine; 1967.

9. Marcellus L. The grounded theory method and maternal-infant research and practice.
J Obstet Gynecol Neonatal Nurs. 2005;34(3): 349-57.

10. Pandit NR. The creation of theory: a recent application of the grounded theory method. Qual Rep. 1996;2(4):1-16. Available from: http://www.nova.edu/ssss/QR/QR2-4/ pandit.html.

11. Chiaravalloti NF. Conhecimintos da população sobre dengue, seus vetores e medidas de controle em São José do Rio Preto, São Paulo. Cad Saude Publica. 1997;13(3):447-53.

12. Christophers SR. Aedes aegypti (L) the yellow fever mosquito: its life, history, bionomics, and structure. London: Cambridge University Press; 1960. Pp. 54-75.

13. Claro LBL, Tomassini HCB, Rosa MLG. Prevenção e controle do dengue: uma revisão de estudos sobre conhecimentos, crenças e práticas da população. Cad Saude Publica. 2004; 20(6):1447-57.

14. Fajardo P, Monge CA, Lozano G, Realpe O, Hernández LE. Nociones populares sobre "dengue" y "rompehuesos", dos modelos de la enfermedad en Colombia. Rev Panam Salud Publica. 2001;10(3):161-8.

15. Gordon AJ. Mixed strategies in health education and community participation: an evaluation of dengue control in the Dominican Republic. Health Educ Res Theory Pract. 1988; 3(4):399-419.

16. Gordon AJ, Rojas Z, Tidwell M. Cultural factors in Aedes aegypti and dengue control in Latin America: a case study from the Dominican Republic. Int Q Community Health Educ. 1990;10:193-211.

17. Koss J. Final report: innovative educational approaches to the prevention of dengue and dengue hemorrhagic fever in Puerto Rico. Al- buquerque: University of New Mexico, Department of Psychiatry; 1988.

18. Lloyd LS, Winch P, Ortega-Canto J, Kendall C. The design of a community-based health education intervention for the control of Aedes aegypti. Am J Trop Med Hyg. 1994;50(4):401-11.

19. Panagos A, Lacy ER, Gubler DJ, Macpherson CNL. Dengue in Grenada. Rev Panam Salud Publica. 2005;17(4):225-9.

20. Winch PJ, Lloyd LS, Godas MD, Kendall C. Beliefs about the prevention of dengue and other febrile illness in Mérida, Mexico. Am J Trop Med Hyg. 1991;94:377-87.

21. Castle T, Amador M, Rawlins S, Figueroa JP, Reiter P. Absence of impact of aerial malathion treatment on Aedes aegypti during a dengue outbreak in Kingston, Jamaica. Rev Panam Salud Publica. 1999;5(2):100-5.

22. Gubler DJ, Casta-Vélez A. A program for prevention and control of epidemic dengue and dengue hemorrhagic fever in Puerto Rico and U.S. Virgin Islands. Bull Pan Am Health Organ. 1991;25:237-47.

23. Rigau-Pérez JG, Clark GG. Cómo responder a una epidemia de dengue: visión global y experiencia en Puerto Rico. Rev Panam Salud Publica. 2005;17(4):282-93.

Manuscript received on 16 November 2007. Revised version accepted for publication on 14 October 2008. 
RESUMEN Objetivo. A pesar de la prolongada endemia y los reiterados esfuerzos gubernamentales y privados, la participación efectiva y sostenida de la comunidad en las tareas de prevención del dengue sigue siendo un reto en Puerto Rico. A partir de en-

Creencias y prácticas comunitarias relacionadas con el dengue en Puerto Rico trevistas realizadas en 2001 se analizaron las diferencias en las actitudes hacia el dengue y su prevención según el sexo de los encuestados y sus antecedentes de haber sufrido esta enfermedad. Estos resultados pueden servir para desarrollar mensajes dirigidos a promover prácticas de control de Aedes aegypti.

Métodos. Entre septiembre y octubre de 2003 sesionaron 11 grupos focales en San Juan, Puerto Rico. Participaron 59 personas (35 mujeres y 24 hombres) de 18 años o más, identificados a través del sistema de vigilancia de dengue de Puerto Rico. El análisis se basó en la teoría fundamentada o inductiva.

Resultados. Las mujeres consideraban importante el dengue por su impacto económico, emocional y sanitario y más mujeres que hombres estaban preocupadas por la insuficiente recolección de basura y disposición de aguas residuales. Los participantes con diagnóstico previo de dengue estaban más preocupados por los riesgos de la enfermedad, conocían más sobre el dengue y su prevención y con mayor frecuencia aconsejaron el uso de repelentes que sus pares sin diagnóstico previo de dengue. Entre las barreras para la prevención sostenida del dengue estaban: conceptos erróneos por materiales educativos obsoletos, la "invisibilidad" del dengue en comparación con las enfermedades crónicas y la falta de aceptación de responsabilidad por la prevención del dengue.

Conclusiones. Las estrategias sugeridas para motivar la acción de los residentes comprenden: trabajar con las agencias gubernamentales para resolver los problemas estructurales que incrementan las poblaciones de mosquitos, mejorar el acceso a la información sobre la recolección de basura y la disposición de las aguas residuales mediante líneas telefónicas de asistencia directa, aumentar la propaganda y la información sobre el dengue mediante campañas por los medios masivos de información y educar a los profesionales de la salud.

Palabras clave Dengue, educación en salud, control vectorial, Puerto Rico. 